\title{
(6) OPEN ACCESS \\ Changes in angle of optic nerve and angle of ocular orbit with increasing age in Japanese children
}

\author{
Hideyuki Tsukitome, ${ }^{1}$ Yoshikazu Hatsukawa, ${ }^{2}$ Tomoko Morimitsu, ${ }^{2}$ Teiji Yagasaki, ${ }^{3}$ \\ Mineo Kondo ${ }^{1}$
}

${ }^{1}$ Department of

Ophthalmology, Mie University

Graduate School of Medicine,

Tsu, Japan

${ }^{2}$ Department of

Ophthalmology, Osaka Medica

Center and Research Institute

for Maternal and Child Health,

Osaka, Japan

${ }^{3}$ Yagasaki Eye Clinic,

Ichinomiya, Japan

\section{Correspondence to}

Dr Mineo Kondo, Department of Ophthalmology, Mie

University Graduate School of Medicine, 2-174 Edobashi,

Tsu, Mie 514-8507, Japan;

mineo@clin.medic.mie-u.ac.jp

Received 13 March 2014

Revised 29 June 2014

Accepted 25 July 2014

Published Online First

21 August 2014

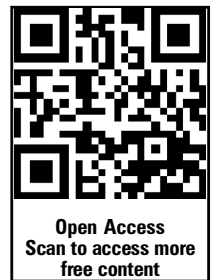

CrossMark

To cite: Tsukitome $H_{\text {, }}$ Hatsukawa Y, Morimitsu T, et al. Br J Ophthalmol 2015;99:263-266.

\section{ABSTRACT}

Purpose To study changes in the opening angle of the optic nerve and the angle of the ocular orbit with increasing age in normal Japanese children.

Methods We studied 147 normal children (aged 6 months to 18 years) who had undergone $\mathrm{CT}$ as a diagnostic procedure. Measurements were performed on axial $\mathrm{CT}$ images that included the entire optic nerve of both eyes. The opening angle of the optic nerve was defined as the angle formed by the intersection of a line running through the left optic nerve and a vertical line passing through the centre of the nose. The opening angle of the orbit was defined as the angle formed by the intersection of a line running tangentially along the deep lateral wall of the left orbit and a vertical line passing through the centre of the nose. The relationship between age and these opening angles was analysed by regression analysis.

Results The correlation between age and opening angle of the optic nerve was not significant. In contrast, the opening angle of the orbit decreased relatively rapidly until about 2-3 years of age, and then it stabilised. The decrease in the opening angle of the orbit with increasing age was significant $(p<0.001)$. The relationship between these two parameters was best fitted by a logarithmic regression curve.

Conclusions Because the opening angle of the orbit decreased significantly with increasing age, this factor must be considered when diagnosing and treating strabismus in children.

\section{INTRODUCTION}

The morphology of the orbit is known to change during normal development. The angle of the orbit is wide during early fetal development and gradually becomes narrower as gestation progresses. ${ }^{1}$ Examining normal developmental changes in orbital morphology after birth should provide important information on the management of strabismus in children with and without skull or orbital abnormalities.

There have been a number of studies on changes in the volume of the orbit and the diameter of the orbital opening during development. ${ }^{2-6}$ However, there are only three studies on the opening angle of the optic nerve or the orbit. $^{7-9}$ Therefore, the purpose of this study was to determine changes in the opening angle of the optic nerve and orbit with increasing age using axial CT images in normal Japanese children.

\section{SUBJECTS AND METHODS \\ Subjects}

We studied 147 children (aged 6 months to 18 years) who had been examined at the Osaka Medical Center and Research Institute for Maternal and Child Health from 2008 to 2011. These children had undergone head CT because they had suffered a blow to the head or had headaches of unknown origin. The attending doctors needed to rule out intracranial injuries or diseases. Children found not to have head or orbital abnormalities served as subjects. Children whose height or weight fell outside the mean $\pm 2 S D$ for their age group were excluded. In addition, children with conditions potentially affecting the normal formation of the skull or facial bones, such as hydrocephalus or craniosynostosis, and also children with apparent eye position abnormalities were excluded. The procedures used conformed to the tenets of the World Medical Association's Declaration of Helsinki. The institutional ethics review board approved this retrospective study of the patients' medical records (approved No 675).

The children were divided into year age groups; to minimise age variations in each age group due to the date of birth, subjects were selected by the following method. Ten infants who underwent CT at 6 \pm 1 months of age were placed in the 6 -month age group. For the 1-8-year groups, 10 children who had undergone CT on their date of birth \pm 1 month were selected. Similarly, of the children who underwent a CT on their date of birth \pm 2 months from ages 9-12 and ages 15-17 years, 10 of each age were selected. Seven children who underwent a CT at age 18 years \pm 2 months were also selected. In total, 147 children were studied. A histogram of the age and sex of these children is shown in figure 1 .

\section{CT and measurement of opening angles}

A CT system (Aquilion16; Toshiba, Japan) was used to obtain tomographic images of the head including both orbits with the optic nerves and the surrounding orbital walls (figure 2). The CT scan was performed with the subject in the supine position with their face directed upward, and measurements were made on the CT image in which the face position was straight upward. Imaging conditions were: tube voltage, $120 \mathrm{kV}$; tube current, $200 \mathrm{~mA}$; slice thickness, $0.5 \mathrm{~mm} ; 16$ data acquisition system channels; helical scan with a pitch of 0.67 . The slice thickness for images used for the measurements was $1 \mathrm{~mm}$. Opening angles of the optic nerve and orbit were measured in the axial CT images.

The opening angle of the optic nerve was defined as the angle formed by the intersection of a 


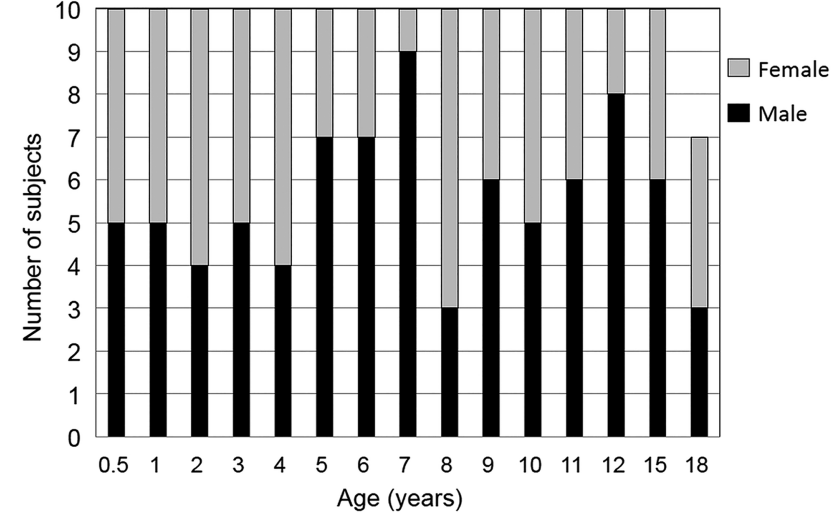

Figure 1 Histogram showing the age and sex of the 147 children who were subjects of this study.

line running through the left optic nerve and a vertical line passing through the centre of the nose (figure 2, left panel). The opening angle of the orbit was defined as the angle formed by the intersection of a line running tangentially along the deep lateral wall of the left orbit and a vertical line passing through the centre of the nose (figure 2, right panel). We measured these angles when the optic nerve appeared in one CT slice. An automatic measuring tool, which was included in the electronic medical charts, was used to measure these angles. To reduce interobserver variation, all measurements were performed by two independent observers (HT and TM), who were blinded to the age of the subject. The mean values of the two observers were used for the statistical analyses.

\section{Statistical analyses}

Mann-Whitney $U$ tests were used to compare opening angles between two groups of different ages. In addition, the following three types of regression analysis were performed to examine the relationship between age and opening angle of the optic nerve or opening angle of the orbit: linear regression analysis using the actual values, linear regression analysis in which the relationship between angle and age was approximated with an exponential function, and linear regression analysis in which the relationship between angle and age was approximated with a logarithmic function. The coefficient of determination $\left(\mathrm{r}^{2}\right)$ and $\mathrm{p}$ values were determined on the basis of these regression analyses. $\mathrm{p}<0.05$ was considered significant.

\section{RESULTS}

The opening angles of the optic nerve in each age group are shown in figure 2 . The mean opening angle of the optic nerve was $23.9 \pm 4.1^{\circ}($ mean $\pm S D)$ in the 10 infants in the 6 -month age group and $21.7 \pm 1.7^{\circ}$ in the 10 in the 3 -year age group (figure 3 ). The difference between these two groups was not significant $(p=0.82$; Mann-Whitney $U$ test). The relationship between age and opening angle of the optic nerve was analysed using three regression analyses (table 1 ). We found that there was no significant correlation between age and angle of the optic nerve $(\mathrm{p}>0.40)$, and the coefficient of determination $\left(\mathrm{r}^{2}\right)$ of age to the opening angle of the optic nerve was less than 0.01 (1\%) for all three regression analyses (table 1 ).

The opening angles of the orbit in each age group are plotted in figure 4 . The mean opening angle of the orbit was $50.8 \pm 4.1^{\circ}$ in 10 infants who were 6 months old, and this was significantly larger than that $\left(45.2 \pm 1.9^{\circ}\right)$ in 10 infants who were 3 years of age $(p<0.001$; Mann-Whitney $U$ test). In addition, the data show that the angle decreased asymptotically up until the age of 2-3 years.

The relationship between age and opening angle of the orbit was analysed using three regression analyses. We found that there were significant correlations between age and angle of orbit for all regression analyses $(p<0.001$, table 1$)$. The coefficient of determination $\left(\mathrm{r}^{2}\right)$ of age to the opening angle of the orbit was about $0.13(13 \%)$ and $0.12(12 \%)$ according to linear and exponential regression analyses, respectively, and 0.19 $(19 \%)$ in the logarithmic regression analysis (table 1).

\section{DISCUSSION}

Body parts change considerably during the fetal period and early childhood. A number of studies have examined morphological changes in the orbit with increasing age, ${ }^{1-9}$ but only a few studies have measured changes in the opening angle of the optic nerve and orbit after birth in normal subjects. ${ }^{7-9}$ We
Figure 2 Opening angle of the optic nerve and opening angle of the orbit for representative typical infants measured on the axial CT image at 6 months and 5 years of age. The opening angle of the optic nerve was defined as the angle formed by the intersection of a line running through the left optic nerve and a vertical line passing through the centre of the nose (left panel). The opening angle of the orbit was defined as the angle formed by the intersection of a line running tangentially along the deep lateral wall of the left orbit and a vertical line passing through the centre of the nose (right panel). There were no major differences in the opening angle of the optic nerve (left panel) in infants at 6 months and 5 years of age, but the opening angle of the orbit (right panel) was less in the 5-year-old infant.

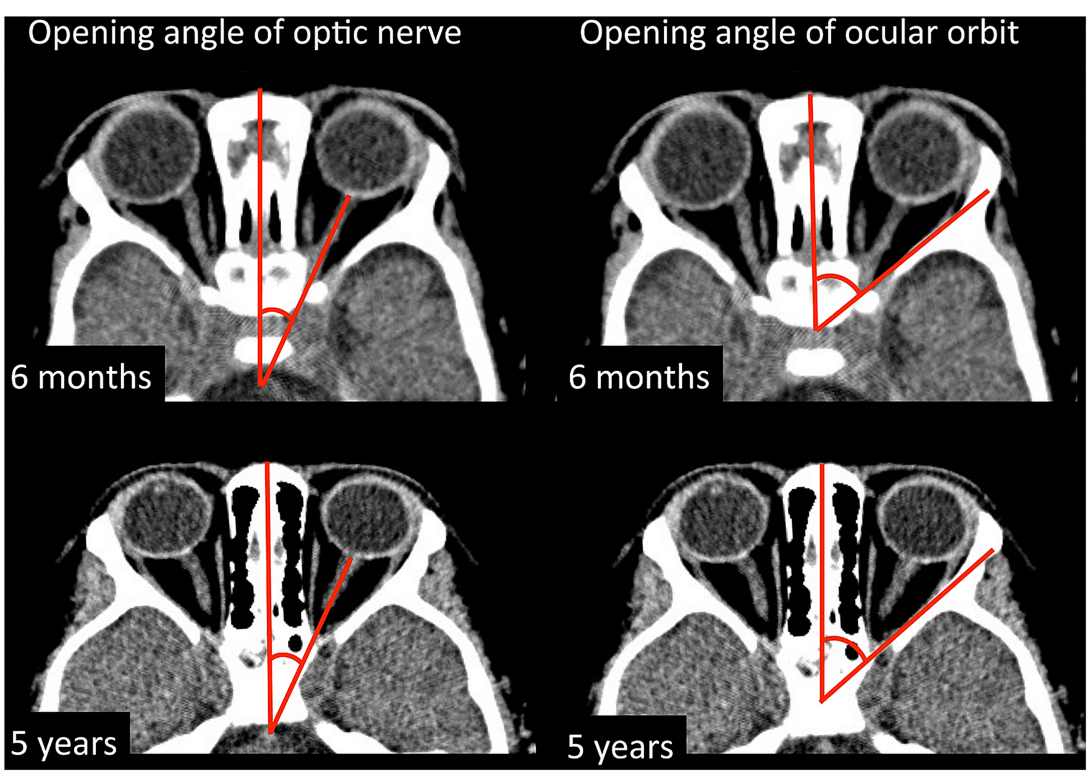




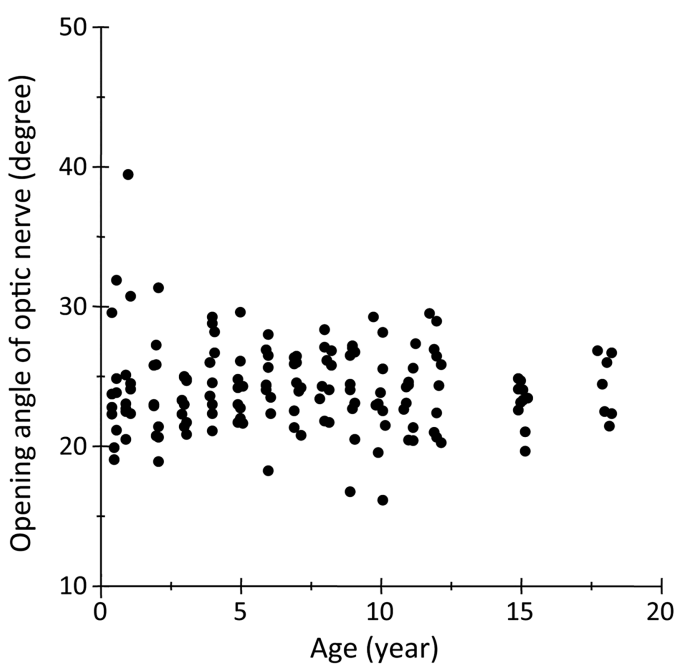

Figure 3 Changes in the opening angle of the optic nerve during development. The results of regression analyses showed no significant changes in the opening angle of the optic nerve with increasing age.

measured the opening angle of the optic nerve and orbit using axial CT images in 147 normal Japanese children aged from 6 months to 18 years.

In an autopsy study, Zimmermann et $\mathrm{al}^{7}$ measured the angle formed by two lines running from the optic chiasm to the site where the optic nerves are attached to each eye. They reported that the opening angle of the optic nerve measured by this method decreased slightly during the fetal period, and that the angle was $\sim 71.5^{\circ}$ at birth and $\sim 68^{\circ}$ in adults. This early study involved measurements on autopsied heads, and the method used to measure the opening angle of the optic nerve differed from that used in our study, so a direct comparison may not be meaningful. However, they found that the opening angle of the optic nerve changed very little during development, which is consistent with our results.

Escaravage $e t a l^{8}$ measured the angle formed by the central axis of the two orbits. They reported that the angle formed by the central axes of the two orbits decreased until about 1 year of age, but changed little thereafter. Although their measurement method was similar to our method for the angle of optic nerves, it was not identical. In addition, Escaravage et al obtained data from many infants whose ages ranged from birth

Table 1 Coefficient of determination $\left(r^{2}\right)$ and $p$ values between age and opening angle of the optic nerve, and between age and opening angle of the ocular orbit obtained by three different regression analyses

\begin{tabular}{|c|c|c|c|c|}
\hline & \multicolumn{2}{|c|}{$\begin{array}{l}\text { Age and opening } \\
\text { angle of optic nerve }\end{array}$} & \multicolumn{2}{|c|}{$\begin{array}{l}\text { Age and opening } \\
\text { angle of ocular orbit }\end{array}$} \\
\hline & $\begin{array}{l}\text { Coefficient of } \\
\text { determination } \\
\left(r^{2}\right)\end{array}$ & $p$ Value & $\begin{array}{l}\text { Coefficient of } \\
\text { determination } \\
\left(r^{2}\right)\end{array}$ & p Value \\
\hline $\begin{array}{l}\text { Linear regression } \\
\text { analysis }\end{array}$ & 0.005 & 0.411 & 0.126 & $<0.001$ \\
\hline $\begin{array}{l}\text { Exponential } \\
\text { regression analysis }\end{array}$ & 0.003 & 0.517 & 0.121 & $<0.001$ \\
\hline $\begin{array}{l}\text { Logarithmic } \\
\text { regression analysis }\end{array}$ & 0.003 & 0.505 & 0.188 & $<0.001$ \\
\hline
\end{tabular}

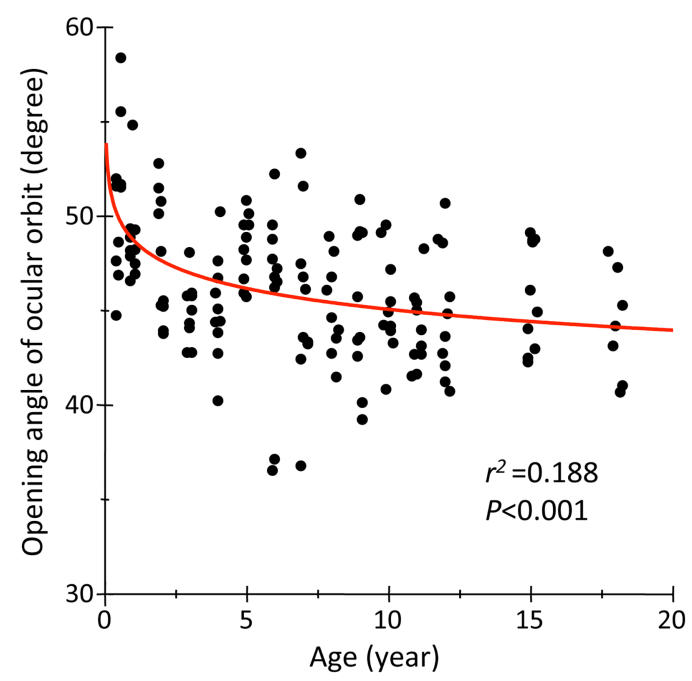

Figure 4 Changes in the opening angle of the orbit during development. The opening angle of the orbit was found to decrease significantly during development. The red line is the logarithmic curve generated by regression analysis $\left(r^{2}=0.188, p<0.001\right)$. Equation: $y$ (angle of ocular orbit, degrees) $=48.7-3.7 \log x$ age (years).

to 6 months, whereas our study included infants $\geq 6$ months of age. Their findings clearly detected changes from birth to the age of 1 year.

There were considerable variations in the opening angle of the optic nerve, particularly in infants younger than 1 year (figure 3). One possible reason for this is that there is a variation in the position of the optic nerve on the CT images of infants younger than 1 year. Another possibility is that the opening angle of the optic nerve was affected by the direction of the eyes during the CT scans, especially in infants younger than 1 year. Alternatively, this variation in the opening angle of the optic nerve may simply be caused by a large variation in the growth of the head and orbit.

There have been studies on changes in the opening angle of the orbit during development. Lemke and Lucarelli ${ }^{9}$ used CT images to measure the opening angle of both orbits, and they reported that the opening angle of the orbits was $\sim 90^{\circ}$ in adults. This angle is similar to that of the teenage group in our study whose ages ranged from 15 to 18 years (unilateral orbital angle, $45.5 \pm 3.5^{\circ}, \mathrm{n}=18$ ).

The measurements in our study indicate that the opening angle of the orbit changed substantially before the age of 3 and changed less thereafter (figure 4). In addition, the results indicate that the changes in the opening angle of the orbit can be fitted by a logarithmic curve. Escaravage $e t a l^{8}$ reported that the angle of the orbit decreased until the age of 1 year and then changed little thereafter. They measured the angle formed by a line connecting the orbital apex and the orbital process of the zygomatic bone and the medial and lateral wall of the orbit (the angle between the medial and lateral orbital wall). We measured the angle formed by the intersection of a line running tangentially along the deep lateral wall of the left orbit and a vertical line passing through the centre of the nose. Thus, a direct comparison is not possible.

We measured the angle formed by the deep lateral wall of the orbit because this wall is where the extraocular muscles are in contact with the orbital bone via a pulley system. This site is closely associated with eye movements and eye alignment. 
Although the relationship between the morphology of the orbit and the presence of strabismus has not been well investigated, strabismus is common in craniosynostosis, with a complication rate of 39-90.9\%. Exotropia is the major type of strabismus in Crouzon syndrome and Apert syndrome. ${ }^{10}$ Kreiborg and Cohen ${ }^{11}$ reported that the incidence of exotropia in Crouzon syndrome was $76.6 \%$ and both the inner and the outer interorbital distances were significantly greater than that of normal orbits, resulting in an increase in the opening angle of the orbits between both lateral walls. Morax ${ }^{12}$ studied changes in the position of the eye in patients with Crouzon syndrome after a sagittal expansion of the orbit. Eight of nine patients were exotropic before the craniofacial surgery, and the exotropia was corrected to orthophoria after the surgery without a strabismic procedure. This change in ocular alignment most likely resulted from the decrease in the opening angle of the orbits between the two lateral walls caused by the surgical procedures. In Apert syndrome, the ocular alignment changed from exotropia to esotropia after craniofacial surgery. ${ }^{13} 14$ These findings suggest that the greater the opening angle of the orbits, the more often exotropia is present.

The results of several studies examining the relationship between exotropia and the increase in the opening angle of the orbits have been reported. It is known that $\sim 70 \%$ of newborns have an exodeviation, but the deviation gradually disappears in most cases by 2-4 months of age. ${ }^{15}$ The reason why this happens has not been determined, but our findings suggest that the decrease in the opening angle of the orbit may contribute to this decrease in exodeviation.

It is known that strabismus often recurs after strabismic surgery. One of the authors (TY) has reported that exotropic patients who have a recurrence soon after surgery tended to have a larger opening angle of the orbit, and that resection of the medial rectus rather than recession of the lateral rectus muscle resulted in fewer recurrences after the surgery. ${ }^{16}$ If this is correct, then the opening angle of the orbit should be considered when the type of exotropia surgery is selected.

Intermittent exotropia is known to be more prevalent in Asians than in Caucasians. ${ }^{17}$ One way to determine the reasons for this would be to study changes in opening angle of the orbit with increasing age in Caucasians and compare them with changes in Asians. Such research might yield interesting findings.

This study has four limitations. The first is that it did not include data from newborns to examine changes soon after birth. This is because there was a lack of data from normal newborns who had undergone CT soon after birth. The second limitation is that this study measured the angle along the optic nerve for the measurement of the opening angle of the optic nerve. However, children have difficulty controlling their eye movements, so measurements may differ from the actual opening angle of the optic nerve. The third limitation is that we did not determine the eye position and eye movements before the CT recordings. The fourth limitation is that there are no data on the changes in angles in one child at different agesthat is, a longitudinal study.

In spite of these limitations, this study revealed that the opening angle of the orbit changes logarithmically with age.
The results provide important information for the management of strabismus in children with and without skull or orbital abnormalities.

Acknowledgements The authors thank Professor Duco I Hamasaki of Bascom Palmer Eye Institute for his critical discussion and editing of the final version of manuscript.

Contributors HT, YH, TY and MK planned this study. HT, YH and TM measured the angle of optic nerves and orbits. HT, YH, TM and MK analysed the data. HT, $\mathrm{YH}, \mathrm{TY}$ and MK wrote the manuscript.

Funding Grant support: Grant-in-Aid for Scientific Research C (No 20592603) from the Ministry of Education, Culture, Sports, Science and Technology (http://www.jsps. go.jp/).

\section{Competing interests None.}

Ethics approval Institutional Ethics Review Board of Osaka Medical Center and Research Institute for Maternal and Child Health (№ 675).

Provenance and peer review Not commissioned; externally peer reviewed.

Open Access This is an Open Access article distributed in accordance with the Creative Commons Attribution Non Commercial (CC BY-NC 4.0) license, which permits others to distribute, remix, adapt, build upon this work non-commercially, and license their derivative works on different terms, provided the original work is properly cited and the use is non-commercial. See: http://creativecommons.org/ licenses/by-nc/4.0/

\section{REFERENCES}

1 Duke-Elder S, Cook C. The post-natal period. In: Duke-Elder S, ed. System of ophthalmology, normal and abnormal development, part 1. Embryology Vol III. London: Henry Kimpton, 1963:304-13.

2 Farkas LG, Posnick JC, Hreczko TM, et al. Growth patterns in the orbital rejoin: a morphometric study. Cleft Palate Craniofac J 1992;29:315-18.

3 Furuta M. Measurement of orbital volume by computed tomography: especially on the growth of orbit. Jpn J Ophthalmol 2001;45:600-6. (in Japanese with English abstract).

4 Bentley RP, Sqouros S, Natarajan K, et al. Normal changes in orbital volume during childhood. J Neurosurg 2002;96:742-6.

5 Yang G, Wang J, Chang Q, et al. Digital evaluation of orbital development in Chinese children with congenital microphthalmia. Am J Ophthalmol 2012;154:601-9.

6 Chau A, Fung K, Yip L, et al. Orbital development in Hong Kong Chinese subjects. Ophthalamic Physiol Opt 2004;24:436-9.

7 Zimmermann AA, Armstrong EL, Scammon RE. The change in position of the eyeballs during fetal life. Anat Rec 1934;59:109-34.

8 Escaravage GK Jr, Dutton JJ. Age-related changes in the pediatric human orbit on CT. Ophthal Plast Reconstr Surg 2013;29:150-6.

9 Lemke BN, Lucarelli MJ. Anatomy of the ocular adnexa, orbit, and related facial structures. In: Black EH, Nesi FA, Gladstone GJ, Levine MR, Calvano CJ, eds. Smith and Nesi's ophthalmic plastic and reconstructive surgery. New York: Springer 2012:3-58

10 Rosenberg JB, Tepper OM, Medow NB. Strabismus in craniosynostosis. J Pediatr Ophthalmol Strabismus 2013;50:140-8.

11 Kreiborg S, Cohen MM Jr. Ocular manifestations of Apert and Crouzon syndromes: qualitative and quantitative findings. J Craniofac Surg 2010;21:1354-7.

12 Morax S. Change in eye position after cranio-facial surgery. J Maxillofac Surg 1984; 12:47-55.

13 Khong JJ, Anderson P, Gray TL, et al. Ophthalmic findings in Apert syndrome prior to craniofacial surgery. Am J Ophthalmol 2006;142:328-30.

14 Khong JJ, Anderson P, Gray TL, et al. Ophthalmic findings in Apert's syndrome after craniofacial surgery: twenty-nine years' experience. Ophthalmology 2006;113:347-52.

15 Archer SM, Sondhi N, Helveston EM. Strabismus in infancy. Ophthalmology 1989;96:133-7.

16 Yagasaki T, Yokoyama Y, Maeda M, et al. Larger biorbital angle in cases with immediate recurrence after surgery for intermittent exotropia. Presented at $2 n d$ World Congress of Pediatric Ophthalmology and Strabismus; 7-9 September 2012, Milano.

17 Chia A, Roy L, Seenyen L. Comitant horizontal strabismus: an Asian perspective. Br J Ophthalmol 2007;91:1337-40. 